\title{
Evidence of Accommodation to L2 Pragmatic Norms in Peer Review Tasks of Japanese Learners of English
}

\author{
Virginia LoCastro \\ Universidad de las Americas, Puebla, Mexico
}

This paper reports on a project examining written peer reviews by Japanese learners of English and is a partial replication of a study conducted by Johnson (1992) on compliments and politeness in peer reviews of native English speaker writers. In addition, this project focuses on the effect of instruction. The literature on the teaching of L.2 pragmatic norms, particularly in a foreign language environment, lacks information on the effect of instruction in academic writing skills on the learners' production, a lack which this study attempts to remedy. The first aim is to assess the learners' use of the speech acts of complimenting, agreeing and disagreeing, and making corrections, as well as the complimenting discourse strategies the learners used when correcting their peers' texts. The second aim is to assess the effects of writing instruction administered within the learners' Intensive English Program. The effect of instruction is examined specifically with regards to the use of the syntactico-semantic device "I think."

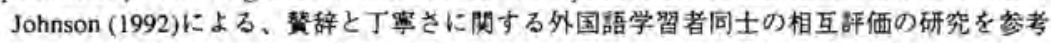
に、本論文では、日本人英語学習者による学習者同士の相互評価を考察した。さらに、特 に外国望の分野においては、第二言語のブラダマティックス教骨の、学術的ライティンダ 能力への効果についての先行研究が十分とは言えず、本研究では、この効果も研究对象と した。研究の目的は、学習者の替辞、同意、反意、訂正なとの発話行為や赫辞ストラテ シーを調ヘ、ざらに、ライティング授業の効果を調くることである。授業効果については 特に"I think"という表現を取り上げた。

A cademic writing programs for learners of English commonly include peer review tasks, whether these are performed orally in pairs/groups or in writing about classmates' essays. The motivation for this task type is that presumably the learners will become more competent at making evaluations of their own essays. However this task could present difficulties for English language learners for at least 
two reasons. First, the cultural background of the learners may lead them to expect feedback on their writing only from their teachers (Nelson \& Carson, 1998). Although the notion that peers are a legitimate source of feedback on writing tasks has become a feature of contemporary American approaches to the teaching of writing, it may not be understood or welcomed by learners with different cultural expectations. Second, even native English speaker (NES) writers may experience difficulties when suggesting that corrections should be made to a peer's work. In the process of providing feedback, the peer's "face" has to be taken into consideration. Too much criticism can alienate the peer while insufficient suggestions for improvement may be discouraging and demotivating, leaving the writer feeling that his/her essay was not adequately reviewed. Furthermore, a low grade on the essay could result in the writer blaming the peer reviewer.

Clearly, peer reviews are not unproblematic as a classroom practice, Yet many teachers currently use peer reviews as a standard practice in their writing classes in English as a second/foreign (ESL/EFL) language contexts. The use of peer editing has been and continues to be a recommended activity in many ESL writing programs (Fowler \& Aaron, 1998). As suggested above, however, what may appear to be a valuable activity may be compromised by a number of aspects, and L2 writing teachers must make informed decisions as to the value of this activity for the learners in their classrooms. In teaching academic writing to non-native speakers of English (NNSs), teachers need to consider two important functions of peer reviews. The first is explicit: to help the learners develop their writing skills. The second is covert: to train them to adopt the norms of American academic writing which include being able to critique and offer corrections for their own essays as well as for peers. The two functions are linked; presumably the second will facilitate the first. The current study addresses the more covert dimension of peer review, that is, the learners' adoption and use of the L2 pragmatic norms associated with critiquing a peer's essay.

This exploratory report examines written peer reviews by 19 Japanese learners of English enrolled in an Intensive English program at a Japanese university, and is a partial replication of a similar study conducted by Johnson (1992) on compliments and politeness in peer reviews of NES writers. In addition to following some of the procedures in Johnson's study, this project also includes a focus on the effect of instruction. The literature on the teaching of L2 pragmatic norms, particularly in a foreign language environment (see Kasper, 1997; Bouton, 1994; Tateyama, Kasper, Mui, Tay \& Thananart, 1997; Sato \& Beecken, 1997) lacks information on the effect of instruction in academic writing 
skills on the learners' production. Although limited, this study attempts to supply some information about instruction effects in the EFL situation.

Here the peer reviews are analyzed for the use of the speech acts of complimenting, showing agreement and disagreement, and giving corrections, as well as for complimenting discourse strategies. The aims are, first, to assess the frequency of these speech acts and discourse strategies in the learners' texts ${ }^{1}$ and, second, to assess the effect of instruction on the writing lessons. The effect of instruction is taken up in particular with regards to one teaching point, the use of the syntacticosemantic device "I think." Within the context of the goals of the learners' EFL writing course, this exploratory study asks if the learners demonstrate evidence of adoption of American rhetorical style. As for the specific syntactico-semantic device, an important question concerns evidence of progress towards NES norms in its use.

An assumption of the present study is that accommodation to the norms of an American-influenced academic writing style with regards to the targeted items constitutes evidence of willingness to adopt L2 pragmatic norms. It is beyond the scope of this paper to address the long-term effects of instruction. Given that the learners involved in this study continued in academic writing classes for two more terms and then another term in their second year, it seems reasonable to assume that a majority of them will seek to internalize the norms. However, further research is strongly warranted. Either a longitudinal study of a similar EFL group or a follow-up study of the same group in their final year at university would be useful to assess more completely the effect of instruction in academic writing.

\section{Issues in Peer Review Tasks}

\section{Assessment of Pragmatic Norms}

The assessment of pragmatic norms both in spoken and written modalities is problematic, for NESs as well as for NNS learners of English (McNamara, 1997). McNamara (1997) points out that in any performance assessment, the "intrinsically social nature" of interactions must be taken into consideration. For example, in an oral interview situation a NES interviewer might ask two Asian students, one male and one female, to make arrangements to go to the movies together. The subsequent silences, disfluencies, and slow speech are clear indications that sociocultural dimensions are likely to be hindering their target language production. Just how the social nature of face-to-face interac- 
tions are to be taken into consideration remains to be resolved within the context of testing of communicative competence.

In addition to the question of what the assessment of pragmatic norms should measure, there is also the problem of how to do so; that is, what type of instrument is needed. Comprehension measurement instruments have included tests or questionnaires which call upon informants to rate or rank choices of appropriate pragmatic behavior (see Kasper \& Dahl, 1991, for a review). NNS responses are then compared with those of NESs. With regards to production, NNSs' pragmatic behavior is typically assessed by Discourse Completion Tests (DCT), role plays, and simulations. Although Hudson, Detmer \& Brown (1995) have developed a multitrait, multimethod approach utilizing role play and self-assessment, there are still questions of reliability and validity which all self-report instruments raise.

Still another concern is the language of the instrument (L1? L2?) and the question of whose norms should be adopted. Within interlanguage pragmatics the issue of whether learners should adopt the norms of the target language community or some yet-to-be defined international community remains controversial. Mey $(1985,1993)$ has argued that pragmatic norms de facto entail a prescriptive approach to language use. However, such a neocolonial perspective has been found to be less than acceptable by Kachru (1982), among others, particularly with regard to the new Englishes in the world.

The assumption that NNSs seek to accommodate to NES pragmatic norms has been embedded in most of the research on second language acquisition and on pragmatic ability (see Kasper \& Schmidt, 1996, p. 156). This assumption has recently been questioned by several researchers (see LoCastro, 1998b). Masumi-So (1998) recommends that contact norms should be co-constructed through discourse and behavior ${ }^{3}$ and Peirce (1995) claims that adoption of L2 pragmatic norms cannot be assumed. In her research on immigrants to Canada, Peirce found that learners may diverge from target language norms when they experience conflict and incongruence between their L1 norms and those of the L2 community, particularly in situations related to the creation of their self-identity in their new community and in work environments. Consequently, although it must be acknowledged that problems of assessment of the L2 learners' pragmatic ability remain unresolved, for the moment self-report data and production in written tasks are arguably suitable measurement instruments for the present study.

\section{Peer Review Activities}

Previous studies of peer reviews focus on response groups. Here groups of learners (perhaps four or five) read one another's essays and 
then discuss the essays in the group, making oral comments. Carson and Nelson (1994) address the issue of cross-cultural differences with regards to collaborative learning, specifically in the context of writing groups. They argue that learners from such countries as Japan and China, which tend to be collectivist, in-group oriented cultures, may provide overly negative feedback to peers in writing groups when these classmates are perceived as out-group members. More recently, Nelson and Carson (1998) looked into ESL students' perceptions of feedback in writing groups. In this case, Spanish-speaking (Mexican and Argentinian) and Chinese students indicated preference for negative (i.e., corrective) feedback from peers and preferably from their teachers. Negative feedback, rather than compliments, was viewed as more helpful to the learners in improving their essays.

\section{Politeness Theory and Face Threatening Acts in Written Texts}

Brown and Levinson's (1987) theory of linguistic politeness provides the theoretical framework for this study, in particular, the decision to examine the use of agreement, compliments and complimenting discourse strategies by NNS informants in the peer review tasks. According to Brown and Levinson, compliments comprise a politeness strategy to redress face-threatening acts (FTA). As Johnson (1992, p. 54) explains, a FTA in a text genre such as a peer review report can be viewed as constituting two types. The first is a global FTA, that is, the entire review or report is a FTA in that it may involve criticism, corrections, and suggestions for improvement. The second is a specific Speech Act, that is, individual criticisms or corrections could be interpreted as FTAs. Consequently, to redress or mitigate the FTA, whether global or specific, compliments are observed at both levels of the text: complimenting discourse strategies at the global level (for example, starting a peer review with a series of positive comments) and individual compliments at the speech act level within the text ("It was easy to understand and stimulating" (Johnson, 1992, p. 57]). The present study also includes an analysis of the instances of the use of corrections based on the assumption that this speech act is an explicit enactment of criticism.

From analysis of her data Johnson identified five discourse strategy categories and three strategies for redressing specific FTAs (Tables 1 and 2).

For redressing global FTAs, Johnson found two types of strategies in her informants' essays. One or more of these strategies were used by her informants. The compliments functioned as softeners before criticisms and suggestions for changes were offered. In addition to Johnson's interest in 
Table 1: Examples of Strategies for Redressing Specific FTAs (from Johnson, 1992)

$\begin{array}{ll}\text { I-A: good news/bad news } & \text { "There is a lot of good information in your } \\ \text { pairing } & \begin{array}{l}\text { paper, and it is clear you understand the } \\ \text { research, but I would like to see more of } \\ \text { your thoughts ..." (p. 65) }\end{array} \\ \begin{array}{l}\text { I-B: good news/bad news } \\ \text { chunking }\end{array} & \begin{array}{l}\text { No example given: strategy similar to I-A, but } \\ \text { involving larger chunks of text. (p, 65) }\end{array} \\ \begin{array}{l}\text { I-C: compliment-as-a-rationale } \\ \text { for suggestion }\end{array} & \begin{array}{l}\text { "Another way [to improve the paper] would } \\ \text { be to expand your explanation of most of } \\ \text { your topics with details and examples. In gen- } \\ \text { eral, I like the topics that were expanded and } \\ \text { explained the most." (p. 65) }\end{array}\end{array}$

Table 2: Examples of Strategies for Redressing Global FTAS (from Johnson, 1992)

U- A: opening strategy

II-B: closing strategy
"1 liked your paper." (p. 66)

"I thoroughly enjoyed reading your paper." (p. 66)

"I found your paper to be very interesting." (p. 67)

"A very interesting paper." (p. 67)

compliments and complimenting discourse strategies, the author of the present study was motivated to include the speech acts of agreement/ disagreement for two reasons. First, the learners' essays in the current study as well as those in another study (LoCastro, 1999) tend to include an explicit statement of agreement. A pragmatic analysis of the use of this speech act suggests that, from the point of view of the peer review writer, expressing agreement is a form of redressive action to mitigate the implied global face-threat of the criticism of the actual peer review. Presumably, by agreeing with the writer, the peer thereby implicates his/her own face as well. If the writer is "wrong" in some way, then so is the peer reviewer. The speech act of agreement can also function as a strategy to redress specific FTAs. In particular, it is often used as a softener before subsequent disagreement (for example, "yes, it's beautiful, but ....") (Pomerantz, 1984). Note that formulaic routines such as "yes, ... but . . ." can also signal an oppositional stance. However, as intonation is an important factor in as- 
signing pragmatic meaning and because the data consisted of written texts, it is not possible to take this possibly confounding variable into consideration in this study. Despite the fact there are no comparable statistics in Johnson's study for the frequency of use of the speech act of agreement or disagreement by NESs, the Japanese learners' essays were analyzed for occurrences of agreement as well as the explicit expression of lack of agreement, that is, disagreement.

The view that compliments and complimenting discourse strategies entail linguistic politeness in written language use is supported by other researchers such as Hyland (1998) and Myers (1989) who claim that mitigation, a form of linguistic politeness, serves to soften FTAs in written academic discourse, as seen in the use of impersonal phrases ("It seems to be the case that ...") and the inclusive "we" ("We have documented ..." ). These linguistic devices carry out the interpersonal function (see Halliday, 1985) of preserving the face needs of the addressee and maintaining rapport. One category of the forms are syntactico-semantic devices such as "I find," "I believe," and "I assume." Johnson (1992, p. 62) found "I think," "I feel," and "I found" in the data she examined. A commonly held view of these devices (see Johnson, 1992; LoCastro \& Sasaki, 1998; Hyland, 1998) is that they are used to hedge the commitment of the speaker to the truth of a proposition. However, a more appropriate view, suggested by Johnson, is that they are also used to compliment and to signal agreement-to redress potential FTAs. According to Johnson (1992), writers "make explicit to their audience that they are offering a personal opinion, and that this opinion may not be shared by others ... (p. 62). Such strategies mitigate a potential FTA by equalizing the P[ower] variable" (her italics, my addition of "power"). In other words, the writer humbles him/herself, thus signaling deference to the addressee or reader. The FTA is mitigated and presumably the "bad news" is more likely to be accepted by the peer.

\section{Japanese-English Pragmatic Norms}

Studies of face-threatening acts such as disagreements and corrections performed by Japanese learners of English indicate that there are differences between the learners' performance of the speech acts and the NESs' performance. This suggests that both pragmatic transfer from the Japanese language as well as different views of social relationships may be encoded in the preferred realization strategies of the two cultures (Beebe \& Takahashi, 1989a \& b; Takahashi \& Beebe, 1993). In a study of chastisement and disagreement, Beebe and Takahashi (1989a) investigated American and Japanese performance of these two FTAs and some important differences were found between the two groups. 
One finding was that the Americans were not always more direct or more explicit than the Japanese. Nikula (1997) obtained similar findings in her comparison of Finnish learners of English and NESs and speculated that this was possibly the result of sociocultural differences and/or the effects of low proficiency. Beebe and Takahashi's data (1989a) suggests that Japanese do not always avoid disagreement (also see LoCastro, 1987) or critical remarks, especially if a higher status person is speaking to someone with lower status. Further, of particular interest for the present study, Beebe and Takahashi report (1989a) that the Americans were found to use compliments and praise more often than the Japanese.

In a related article (1989b), Beebe and Takahashi compared Japanese and American performance of the act of giving embarrassing information in status-unequal situations. They found that the Americans tended to use more positive remarks, more softeners, and, most importantly, fewer explicit criticisms (1989b, p. 113) when addressing a higher-status interlocutor. Two patterns emerged: (a) the use of a questioning strategy to express disagreement, and (b) a quantitative difference in the use of hints to convey embarrassing information. The Japanese used hints differently and more frequently.

In a third study on correction (1993), again with status unequals, Takahashi and Beebe claim that "the most noticeable difference is that 9 out of 14 Americans $(64 \%)$ prefaced their correction with at least one positive remark" (1993, p. 141). Only $13 \%$ of the Japanese working with Japanese subjects did so. Takahashi and Beebe conclude that this is an example of pragmatic transfer from Japanese. The other result with some bearing on the current study concerns the use of softeners to mitigate the force of an FTA, where evidence of transfer from Japanese is also clear, particularly the style-shifting which occurred according to interlocutor status.

While this is by no means an exhaustive review of the literature on Japanese-American English pragmatic norms (see also, for example, Clancy, 1986), the results of the studies support the generation of research questions for the study described in the next sections.

\section{Research Questions}

There are two research questions that motivated the present study:

Research Question One. What speech acts and forms of mitigation do Japanese learners of English use in written peer reviews?

Research Question Two: Is there any evidence of effect of instruction, signaling that the learners seek to accommodate to L2 pragmatic norms? 


\section{Method}

\section{Subjects}

The subjects comprised an intact class of 19 Japanese first year students attending International Christian University (ICU), a bilingual Japanese-English university in Tokyo. From diverse majors, they were enrolled in a 16-hour-a-week Intensive English Language program as well as other classes. One third of the class was male, and two thirds female, reflecting the overall ratio of the student population at the university, Regarding the learners' initial English language proficiency, at the time of this research the TOEFL scores for the ICU students averaged 550, ranging from a low of 500 to a high of 590 . The two teachers ${ }^{5}$ instructing the learners openly discussed their desire to conduct a small research project during the term. For a detailed analysis of speech act usage over time, four learners (two female and two male) were selected at random from the 19 learners in the class.

\section{Instruction}

The subjects had just begun their college life and one of the main purposes of the Intensive English program was to develop their awareness and understanding of academic tasks in the English language. The integrated program can be considered as a form of acculturation to the English language for academic purposes. The ten-week term was split up into the following three-to-four-week topic areas: (1) educational values, (2) critical thinking, and (3) argumentation. The classes met for two 70-minute periods per week. In addition, a third class on academic writing met once a week for 70 minutes for the entire 10 weeks. For the three classes, the learners had one teacher, the author of this study, and although separately labeled "Reading and Discussion" (RD) and "Writing" for administrative purposes, the two types of classes were taught in an integrated manner. Furthermore, the same group of learners also met twice a week with the second teacher for "Reading Strategies" and "Reading Comprehension" classes, each for 70 minutes. The second teacher collaborated with the author by explicitly reinforcing what the learners were studying in the RD and Writing classes through use of related material and by adjusting her lesson content to complement the lessons used with the RD and Writing classes.

In all skill areas the learners were expected to become competent in the use of situationally appropriate L2 language forms. Educational values and critical thinking classes aimed at developing skills for such tasks as eliciting questions, expressing disagreement, and articulating challenges to unexamined thinking and statements. Argumentation was 
taught both as a content topic as well as a process they were expected to adopt and use in essay writing and in group discussions. The oncea-week academic writing class directly taught the learners to accommodate to the norms of Western academic rhetorical styles in writing essays.

Instruction in academic writing consisted of four sources of input: (a) the textbook (Fowler \& Aaron, 1998), (b) classroom instruction, (c) written feedback on their essays from the teacher, and (d) oral feedback from the teacher during writing tutorials. In addition, since the program included weekly lectures for listening comprehension practice, the content of at least two of the lectures also provided a source of input as they focused on details of Western versus Eastern rhetorical styles of academic writing (LoCastro, 1998a). Here is an example of the information provided to the learners in the textbook that is specifically related to the peer review tasks.

\section{Commenting on Others' Writing}

1. Be sure you know what the writer is saying, If necessary, summarize the paper to understand its content.

2. Read closely and critically.

3. Unless you have other instructions, address only your most significant concerns with the work.

4. If you point out every flaw you detect, the writer may have trouble sorting out the important from the unimportant.

5. Be specific. If something confuses you, say why. If you disagree with a conclusion, say why.

6. (deleted)

7. (deleted)

8. Word your comments supportively. Question the writer in a way that emphasizes the effect of the work on you, the reader ... and avoid measuring the work against a set of external standards.

9. Be positive as well as honest. Instead of saying "This paragraph doesn't interest me," say "You have a really interesting detail here that seems buried in the rest of the paragraph." And tell the writer what you like about the paper (Fowler \& Aaron, 1998, pp. 80-81).

Such "advice pages" are found throughout the textbook and the learners were asked to refer to this particular page when they were engaged in writing the peer reviews used in this study. 
At both the macro level of the intensive English for academic purposes program and the micro level of individual class sessions, a major assumption is that the program encourages the learners to adopt the pragmatic norms of the target language academic community. This expectation underlies all the classes of the intensive English program,

\section{Teaching Point}

The specific example of instruction on L2 pragmatic norms used in this study involves a syntactico-semantic device frequently found in the essays of Japanese learners of English: "I think." This is a direct translation of to omou in Japanese, a phrase which occurs with high frequency in both spoken and written L1 discourse (Netsu \& LoCastro, 1997; LoCastro \& Sasaki, 1998) where it usually functions as a hedge to mitigate statements of opinion. Although "I think" does appear in sentence-initial position in essays and talk in NS English, Japanese learners tend to overuse it, as the data collected demonstrated, and, moreover, have difficulty using alternate expressions, limiting themselves to " 1 think" (LoCastro \& Sasaki, 1998). The use and misuse of this device was made a teaching point in four lessons. Some suggestions of alternative phrases, such as "I believe" or "perhaps" were made; they were not, however, the focus of any lesson. In the learners' fluency journals, kept for extensive writing purposes and to promote meta-awareness of L2 features, they were asked to comment on the following questions in three separate entries:

1. What are the differences among the following words: fact, opinion, and belief?

2. How do you feel about learning to give your opinion in a Western style in group discussions and in general?

These two questions address possible cross-cultural differences in the conceptualization of the three concepts as well as in the learners articulated concerns about giving opinions, a speech act they perceive as common among NESs, and one which they claim to aspire to use with fluency.

3. Why do you think Japanese learners tend to use "I think" frequently when they write or talk?

With regards to this question, the teacher had not yet explicitly addressed the use of "I think" in class activities. Following this inductive approach to the use of the syntactico-semantic device, the learners were then asked to make suggestions in a lesson for changes in an 
essay written by a student from a different class who had frequently used "I think." The following day, one point of the class discussion was the use of "I think" vis-à-vis the frequency of to omou in the L1.

\section{Procedures}

The 19 learners were assigned two peer reviews approximately one month apart, on April 20 and May 26, 1998, in order to assess their ability to write a peer review as well as the effect of instruction on "I think" as demonstrated in their writing. The learners were instructed to trade their essay drafts, read their partner's essay and then to write a letter (the peer review) to their partner following the instructions on the handout (see Appendix). The peer reviews were written in class, in English, with 40 minutes allotted for completion of the task. The learners signed their peer review letters.

\section{Data Analysis}

As mentioned, the decision to examine the speech acts of complimenting, agreeing/disagreeing, and correction in the analysis of the peer reviews was based partially on the study by Johnson (1992), who examined complimenting in NES peer review texts. In the present study it was assumed that the four speech acts would be sensitive to the effect of instruction. The learners had received instruction on American norms for writing and for feedback on the writing of drafts. The instruction on American norms specifically emphasized (a) complimenting an interlocutor, especially before performing an FTA, (b) showing disagreement when warranted, and (c) giving corrections, i.e., clear, precise feedback about grammar, spelling, organization, and content of a peer's essay.

Consequently, the occurrences of each speech act (compliments, corrections, signals of agreement and disagreement) as well as occurrences of complimenting discourse strategies were tallied for the peer reviews. In addition, occurrences of "I think" were counted. To answer the first research question, frequency data from four subjects are presented and discussed below, and, for the second research question, aggregate frequency data from the 19 learners in the class are presented to indicate change in response to instruction. Only descriptive statistics are used to compare the two sets of peer reviews by the four learners in this exploratory study. However, one-way adjusted chi square procedures are used to determine the significance of frequency differences for the counts of the aggregate data before and after instruction. It was not possible to carry out inter-rater procedures to determine the reliability of the coding. 


\section{Results and Discussion}

The results of the data collection addressing the first research question are presented below. Here an analysis of the four learners' performance on the peer reviews indicates use of the targeted items. A discussion of these findings follows. Then, an aggregate view of the work of all 19 informants and their use of the syntactico-semantic device is presented and discussed, as the second research question concerning the effect of instruction is addressed.

\section{Research Question One}

What speech acts and forms of mitigation do Japanese learners of English use in written peer reviews?

Results of the analysis of the tasks of the four subjects are displayed in Tables 3 through 6. Although case studies involving only four subjects do not produce generalizable data, an exploratory approach was adopted in order to generate a picture of the learners' behavior.

\section{$\mathrm{Momoko}^{7}$}

The speech acts used in Momoko's peer reviews are shown in Table 3

Table 3: Comparison of Peer Reviews for Momoko

\begin{tabular}{lcc}
\hline Speech Acts & April Peer Review & May Peer Review \\
\hline Compliments & 4 & 5 \\
Agreements & 2 & 1 \\
Disagreements & 0 & 0 \\
Corrections & 2 & 9 \\
Complimenting Strategies & II-A & II-A, II-B \\
I think & 3 & 0 \\
\hline
\end{tabular}

Between the April and May reviews, Momoko increased her use of compliments by one and decreased her use of agreement tokens by one. There were no instances of disagreement either in April or May. The most noticeable change was an increase in the use of corrections and complimenting discourse strategies. There was a decrease in the use of " 1 think" from three instances in April to none in May.

\section{Sbinsuke}

The profile of Shinsuke's use of the targeted speech acts is found in Table 4. 
Table 4: Comparison of Peer Reviews for Shinsuke

\begin{tabular}{lcc}
\hline Speech Acts & April Peer Review & May Peer Review \\
\hline Compliments & 3 & 8 \\
Agreements & 2 & 2 \\
Disagreements & 1 & 0 \\
Corrections & 4 & 6 \\
Complimenting Strategies & II-A & II-A, II-B, I-A, I-B \\
1 think & 9 & 3 \\
\hline
\end{tabular}

Shinsuke used the speech act of agreement an equal number of times in April and May but decreased his use of disagreement by one between April and May. There was a noticeable increase in the use of compliments in the peer reviews and a decrease in the use of "I think" between April and May. The second peer review shows Shinsuke using more complimenting discourse strategies as well.

\section{Mayumi}

The speech acts used in Mayumi's peer reviews are shown in Table 5.

Table 5: Comparison of Peer Reviews for Mayumi

\begin{tabular}{lcc}
\hline Speech Acts & April Peer Review & May Peer Review \\
\hline Compliments & 4 & 8 \\
Agreements & 1 & 1 \\
Disagreements & 0 & 1 \\
Corrections & 3 & 7 \\
Complementing Strategies & II-A, II-B & I-B, II-A, II-B \\
I think & 4 & 1 \\
\hline
\end{tabular}

Mayumi did not use the speech acts of agreement or disagreement either in April or in May. However, there was a clear increase in the number of compliments and corrections and a small increase in the use of complimenting discourse strategies. She also used "I think" less frequently.

\section{Tsuneo}

Tsuneo showed no change in the use of the speech act of agreement but there was a small increase in the use of disagreement (Table 6). There was a noticeable increase in the use of correction and a decrease 
in the number of times (from four to one) in use of "I think." There was also a small increase in the use of complimenting discourse strategies,

Table 6: Comparison of Peer Reviews for Tsuneo

\begin{tabular}{lcc}
\hline Speech Acts & April Peer Review & May Peer Review \\
\hline Compliments & 6 & 4 \\
Agreements & 1 & 1 \\
Disagreements & 0 & 1 \\
Corrections & 3 & 7 \\
Complimenting Strategies & II-A, II-B & I-B, II-A, II-B \\
I think & 4 & 1 \\
\hline
\end{tabular}

\section{Discussion of Research Question One}

With regards to complimenting, either as a speech act or discourse strategy, the limited results suggest that there was a slight tendency to use compliments more frequently in the May reviews. In addition, all of the learners utilized the speech act of correction more frequently and the syntactico-semantic device "I think" less frequently in the second peer review, indicating a possible effect of instruction.

\section{Research Question Two}

Is there any evidence of effect of instruction signaling that the learners seek to accommodate to L2 pragmatic norms?

\section{Effect of Instruction}

Table 7 displays the aggregate findings from the analysis of the two peer review sets, At both times, 19 informants participated in writing the reviews.

Table 7: Aggregate Results for the Two Peer Reviews $(n=19)$

\begin{tabular}{lcc}
\hline Speech Acts & April Peer Review & May Peer Review \\
\hline Compliments & 72 & 81 \\
Agreements & 13 & 14 \\
Disagreements & 1 & 2 \\
Corrections & 46 & $128^{*}$ \\
\hline
\end{tabular}

-Significant at $p<, 05$ 
The data indicate that the informants used compliments, agreements, and disagreements in both sets of peer reviews with essentially the same frequency of occurrence. The noticeable difference concerns the corrections of their peers. There was a $178 \%$ increase in the number of corrections between the first and second peer reviews (chi square df $1=3.84 ;$ chi square obs df $1=38.64 ; p<.05$ ), indicating a significant effect of instruction. The increase is greater than that for the number of compliments ( $12.5 \%$ between the April and May peer reviews).

Since the Johnson study did not assess correction, the increase in the use of corrections by the learners in the present study cannot be compared with other data. However, there seem to be four possible explanations for the increase. The first is the effect of instruction Japanese learners of English tend to hesitate when asked to critique a peer's work in a public setting. Because of this tendency, instruction in the writing and discussion courses in the Intensive English program focused on helping them become more explicit in classroom tasks as well as in self and peer editing. Second, the teachers provided detailed feedback on the learners' work, behavior that the learners could have modeled. A third interpretation concerns stereotypes about Japanese use of face-threatening speech acts; specifically, it is assumed that they avoid such acts as correction, disagreement, and chastisement. However, the studies reported in LoCastro (1987), Beebe and Takahashi $(1989 \mathrm{a} ; 1989 \mathrm{~b})$ and Takahashi and Beebe (1993) suggest that such assumptions may be stereotypes. There may be less reticence than expected in using these FTAs. The research cited above also indicates that the Japanese learners used fewer hedges than the Americans did.

The informants in the present study were peers, i.e., status equals and in-group members. Thus, corrections of a peer's work may entail less attention to face. On one hand, as in-group status-equal peers from the same ethnic background, the informants might have expected to be less harsh and make fewer suggestions for corrections. On the other hand, because they are peers, they might have assumed their suggestions for corrections would be tolerated, even welcomed. It is well known that negative statements are better tolerated when coming from friends than from out-group members.

In addition, the corrections have to be considered in the context of the whole essays, that is, from the global point of view. Of the two sets of 19 essays, all but two informants placed their corrections in the middle sections, in between the introductions and conclusions, where most of the complimentary and agreement language behavior was found. Only two learners, one male and one female, noticeably deviated from that pattern, seemingly dispensing with face-redressive language, to 
zero in directly on corrections. The other 17 learners may have increased the number of corrections, modeling their behavior on what they had been taught and experienced in the tutorials with their teachers, while believing that the complimenting and other face-redressive behavior in the beginning and concluding paragraphs would override the face threat of the corrections. Retrospective interviews with the learners about their writing strategies in the peer reviews would be valuable if this exploratory study were to be replicated.

Finally, in an effort to attain the perceived norms of NES language use, it is possible the learners overused the speech act of correction in a form of "hypercorrection," that is, they may have made more suggestions for corrections than one might expect to find in a NES's peer review. Beebe and Takahashi (1989b, p. 119) label this type of language behavior a "stereotype-induced error." Here the learners may believe that NESs use more direct linguistic signals of criticism than would actually be found in NES or Japanese discourse. Further studies are needed to confirm this generalization.

Of the possible explanations it seems most likely that the increase in the use of corrections and the decrease in the use of "I think" are the result of instruction. The learners may have assumed that they had been asked to offer corrections (one even provided a numbered list) as the main goal of the peer review. There are no statistics on what NESs would produce in the same context, nor are there comparison data of what the Japanese EFL learners would do in a similar situation in a Japanese writing class. However, it is suggested that the learners focused on the instructed element, that is, suggesting corrections, and that they attempted to complete the assignment as they believed that it should be done.

\section{Complimenting Discourse Strategies}

The frequency of the 19 learners' use of complimenting discourse strategies in the peer reviews is shown in Table 8 . These are aggregate figures; that is, for example, in the April essays, there were three learners who used the good news/bad news pairing strategy. It is to be noted that the learners may have used the same strategy more than once in their essays.

The figures suggest three areas of increase: strategies I-A (good news) bad news pairing), I-C (compliment-as-a-rationale-for-suggestion), and II-A (opening strategies). Here a comparison of the number of Japanese learners who used the strategies with that reported for the NESs in Johnson's (1992) study is possible. For the first strategy (I-A), about $40 \%$ of her informants used it once or twice (Johnson, 1992, p, 65). Of the 19 
Table 8; Frequency of Learner Use of Complimenting Discourse Strategies $(n=19)$

Complimenting April

May

Discourse Strategies

1. For redressing specific FTA

I-A. Good news/bad news pairing

I-B. Good news/bad news chunking

[-G. Compliment-as-a-rationale for suggestion

36

$5 \quad 5$

$0 \quad 5$

II. For redressing global FTA

II-A. Opening strategy

II-B. Closing strategy

14

18

$4 \quad 5$

informants in the present study, six $(37 \%)$ used the good news/bad news pairing strategy in May, an increase over the three who used it in April. With regards to (I-B), Johnson found that $16 \%$ of her informants used it whereas $10(58 \%)$ Japanese learners used it at least once. There was no change from the April to May essays. Concerning the compliment-as-a-rationale for suggestion strategy (I-C), Johnson claims that only one writer used it in the data she collected (Johnson, 1992, p. 66). In the present study, there were five informants who used it in the second peer reviews (Table 8). As for the redressing of global FTAs strategy, Johnson indicates that $84.3 \%$ of her informants used one or more opening compliments (1992, p. 66). In the April peer reviews, 14 $(74 \%)$ made some kind of positive opening comment, whereas in the May data, 18 (95\%) of the 19 learners used the opening complimenting strategy one or more times (in some cases more than one paragraph was composed of complimentary remarks). Concerning the closing complimenting strategy, Johnson found that $50 \%$ of the writers in her study used it (Johnson, 1992, p. 66), while a total of nine (47\%) of the informants here utilized it.

Thus, the results in Table 8 suggest a slight tendency for the Japanese learners to use more of the strategies in comparison to the NESs in Johnson's study, the result perhaps of overgeneralizing from instruction which had sensitized them to "saying something positive" before making negative comments. In particular, the Japanese learners used the I-B strategy more frequently: $58 \%$ in comparison to $16 \%$ in Johnson's study. One likely explanation concerns the analytic framework. It is difficult to separate the good news/bad news pairing from the good news/bad news chunking strategy. Clearly, further research in the use of these strategies over a longer period of time (perhaps six months to 
a year) is necessary to assess the full extent of accommodation to L2 pragmatic norms.

It is also possible that the norms for this kind of task in English and Japanese are largely congruent, although there are no data available for the use of complimenting strategies in Japanese texts of the same genre. In general both Johnson's informants and those in the present study tended to prefer the global strategies, i.e., mitigating the face threat of the entire essay. These results support Brown and Levinson's (1987, p. 22) contention that mitigation is more likely to be implicated by a whole utterance rather than by individual markers. The peer reviews in a general way may implicate pragmatically that the peer reviewer is essentially complimenting and agreeing with the writer, while individual sentences may be critical and face-threatening.

In order to demonstrate actual strategy use by the informants, two examples of the peer reviews are presented below. These are both unedited, with the names changed. In both examples the first paragraphs are made up of discourse complimenting strategies while the second peer review demonstrates how such strategies can be used in the final paragraph as well.

\section{Example 1}

Dear 'Yuki,

I am very interested in your essay. You say "education for entering the college prevent HS students form more useful education in HS. And more Japanese lose their purpose in college because their purpose will be to entering college itself. And not only we but Japanese society need to make efforts to change this situation." That is good idea. I also really think so. I think now in many HS the end to enter the college justifies the means to study for Ojuken (study for entrance examinations) and not to study what we need truely. Your explain is very clear and what you want to say is well limited on a few things.

But I want to told you some advice. In paragraph 4, you say many students do a club activity without studying because of lacking of purpose. But one of my friends says my purpose of college is to make friends, and to achieve that is more important than to study. Your opinion, and he has his own belief, that to study is more important in college is only your opinion. What do you think of this opinion? and How do you answer about this question. If you can answer clearly and add to the essay, your belief will be more effective, true, I think. 
Another advise I want to say is about Paragraph I. It is good introduction, but $\mathrm{I}$ expect of you to add to your opinion, for example, from paragraph IV.

\section{Example 2}

Dear Motoko,

I have read your essay about democracy. Your point of view is that Japan is not democratic because there are some undemocratic issues in this country. The most excellent point of your essay is you tried thinking about democracy and making its definition. It is showing your honest attitude to the question previously given.

Let me comment the structure. You used two examples to strengthen your opinion. But the balance of 1 st and 2 nd is not good as to the amount. You might as well widen 1st or shorten 2nd. And you didn't need to divide the conclusion two parts since they can be connected as to the content. However, basic frame is very clear and easy to understand.

Next, grammatical issues, 5th paragraph, line 4, "democracy" should be changed into "democractic." 3rd paragraph, line 3 , "can't, 4th paragraph line 1, "I'd." You should not use shortened expression in essay.

Spelling, there are no mistakes as far as I saw.

Let us move on to more details about the content. You criticized indirect system of election of the Prime Minister. But I don't think it is undemocratic because if members in the Diet are very similar to the general public, there are no problems using indirect system. The problem is, how to elect members in the Diet, not the indirect system itself, I think.

I have criticized your essay, but your claim is reasonable. I agree to your opinion to the most extent. Especially, the example of marine heliport in Okinawa is very persuasive. It is good example to convince people, because we know the problem to some extent. Thank you for reading this letter till the end.

In the first example the peer reviewer creates a first paragraph of compliments and a quotation from the classmate's essay, thereby demonstrating use of Johnson's opening strategy II-A. The second paragraph introduces some criticism of the writer's essay in the form of citing another opinion that is contrary to that of the writer. The peer reviewer appears to be using the opinion as a strategy to get the writer 
to change or correct his/her essay. Citing an outside source may make the comment less threatening than if the peer reviewer directly commented on the writer's view. Here a sentence-final use of "I think" is observed. The third paragraph contains an example of a "good news/ bad news pairing" (I-B) strategy. The peer reviewer compliments the writer's introduction before suggesting a correction.

The second peer review starts with a first paragraph composed of "good news ${ }^{n}$ complimentary comments. The second paragraph is mixed. The second and third sentences together form an example of a good news/bad news pairing strategy. The last two sentences of the second paragraph do so as well, but in reverse, with a bad news/good news pairing.

The next two short paragraphs comment on grammar, lexis, and spelling. In the next to the last paragraph, the peer reviewer returns to the content and indicates disagreement with the writer's point of view. At the end of the fourth paragraph, there is a sentence-final use of "I think." However, its function here is ambiguous. It may be a hedge to soften the peer reviewer's statements, or it may function as a maximizer emphasizing that it is the peer reviewer's point of view. The final paragraph resembles the first; it is an example of use of the global closing strategy comprised of compliments (II-B).

\section{The Syntactico-Semantic Device "I Think"}

In addition to compliments, agreements, and complimenting discourse strategies to redress FTAs and disagreements and corrections to provide potentially unwelcome feedback, this report also examines the effect of instruction on a targeted syntactico-semantic device, In the data collected, there is a noticeable change in the number of tokens of the phrase "I think" and a slight increase in the use of related devices.

Table 9: Frequency of Learner Use of Syntactico-Semantic Devices

\begin{tabular}{lcc}
\hline Phrases & April 20, 1998 & May 26, 1998 \\
\hline I think & 57 & 16 \\
I guess & 2 & 4 \\
In my opinion & 0 & 1 \\
I feel & 0 & 0 \\
\hline
\end{tabular}

As "I think" had been a teaching point in parts of four lessons during the term, the effect of instruction can be observed as a $72 \%$ decrease in its use. However, the hoped-for outcome of an increase in the variety of 
syntactico-semantic devices used to carry out the function of mitigating the FTAs by the writer did not occur. As the author has demonstrated in other related studies (Netsu \& LoCastro, 1997; LoCastro \& Sasaki, 1998), "I think" is a complex, multifunctional pragmatic marker which warrants more attention in the teaching of English to Japanese learners.

\section{Conclusion}

This limited exploratory study suggests that the picture of the learners' progress in the direction of adopting L2 pragmatic norms for academic writing is mixed. The peer reviews for the four learners show a tendency towards increased use of the targeted speech acts and strategies. For the group as a whole the aggregate picture demonstrates a significant increase in the use of corrections with a smaller increase in use of compliments and complimenting strategies.

Second, and this is perhaps the main conclusion, there also appears to be an effect of instruction. The learners significantly increased the number of suggestions for corrections and decreased the use of "I think." Both were targets of the lessons in the writing course so it does appear that instruction may help learners move towards adoption of L2 pragmatic strategies.

As the learners had only been studying academic writing skills for one ten-week term, their progress would undoubtedly be slow in accommodating to the American-influenced pragmatic norms for such a writing genre. Ideally it would be useful to study how academic writing is taught in the learners' L1 to obtain comparison data; however the cultural practices in Japanese universities usually do not facilitate this type of collaborative research.

The question arises at this point whether the results of this limited study provide any insights into the learners' adoption of L2 pragmatic norms for critiquing a peer's essay. Given the assumption that suggesting corrections is a desirable feature of a peer review, it seems possible to argue that the informants' work shows a shift towards the targeted norms. Further, another tendency towards accommodation to the L2 norms is observable in the informants' decrease in the use of "I think." While these conclusions cannot be generalized beyond this study and its small sample size, they clearly suggest areas for further study and may encourage more explicit instruction and materials for the teaching of academic writing, in particular the difficult balance between corrective feedback and face-redressive strategies.

Further research on the value of peer reviews is clearly warranted, particularly in EFL contexts. If the purpose of such an activity is to 
provide feedback so that the novice EFL writers can learn to improve their own essays, then the question must be raised as to whether or not such an approach is the most effective in achieving that goal. From a cross-cultural perspective the studies of Carson and Nelson (1994) and Nelson and Carson (1998) as well as the present study suggest that some EFL or ESL learners may experience peer reviews, whether carried out orally or in writing, as a speech event that is alien to their cultural background. Consequently, teachers of writing must ask if the aim is to acculturate the learners to perform what is to them a new speech event, or to help the learners improve their academic writing skills, or to achieve both aims. This is an interesting pedagogical dilemma and is a subject for further research and debate. Despite the frequent use of the term "norms," too little research is available on the subject to inform classroom teachers' practices.

\section{Acknowledgements}

The author wishes to thank the two anonymous JALT Journal reviewers for their valuable comments.

Virginia LoCastro, Professor of Linguistics at La Universidad de las Americas, Puebla, Mexico, taught in Japan for the Language Institute of Japan, Simul International, Columbia University - Teachers College Masters Program in TESOL, Tsukuba University, Ibaraki, and International Christian University. She is the author of numerous teaching and learning materials as well as book chapters and articles on pedagogy and research in interlanguage and cross-cultural pragmatics, classroom research, and contrastive linguistics.

\section{Notes}

1. Unfortunately, the Johnson paper does not give statistics on the use of agreement and disagreement and thus a more complete comparative study is not possible.

2. Johnson (1992) uses the term "syntactico-semantic device." Another possible term would be "parenthetical verbs," following the practice in the literature on mitigation (Urmason, 1952).

3. While written texts do not involve the same degree of interactional coconstruction of norms as spoken language does, there is nevertheless the presence of the audience which the writer must attend to in creating a written document.

4. The author is well aware of the danger of any discussion about Japanese learners of English bordering on the use of stereotypes, and has actually supported an alternative perspective (see LoCastro, 1996, for example). Further, the author is also aware of and agrees with Kubota's (1995) stance regarding what she labels the acculturation model for teaching ESL. The discussion in the present paper does not in any way imply that the infor- 
mants should adopt the 1.2 norms; the study is an attempt to examine some classroom practices.

5. The author would like to acknowledge the help and cooperation of Atsuko Watanabe of International Christian University in carrying out this project.

6. The parts that have been deleted are not directly relevant to the present study.

7. Pseudonyms have been used.

\section{References}

Beebe, L., \& Takahashi, T. (1989a). Do you have a bag: Social status and patterned variation in second language acquisition. In S. Gass, C. Madden, D. Preston, \& L, Selinker (Eds.), Variation in second language acquisition (pp. 103-125). Clevedon, Avon: Multilingual Matters.

Beebe, L, \& Takahashi, T. (1989b). Sociolinguistic variation in face-threatening speech acts: Chastisement and disagreement. In M. Eisenstein (Ed.), The dynamic interlanguage: Empirical studies in second language variation (pp. 192-218). New York: Plenum Press.

Bouton, L. (1994). Conversational implicature in a second language: Learned slowly when not deliberately taught. Journal of Pragmatics, 22, 157-167.

Brown, P., \& Levinson, S. (1987), Politeness: Some universals of language usage. Cambridge: Cambridge University Press.

Carson, J.G., \& Nelson, G.L. (1994). Writing groups: Cross-cultural issiues. Journal of Second Language Writing, 3, 17-30.

Clancy, P. (1986). The acquisition of communicative style in Japanese. In B. Scheifflein \& E. Ochs (Eds.), Language socialization across cultures (pp. 213249): Cambridgè: Cambridge University Press.

Fowler, H.R., \& Aaron, J.E. (1998). The little brown bandbook (7th ed) New York: Addison Wesley Longman, Inc.

Halliday, M.A.K. (1985), An introduction to functional grammar London: Edward Arnold.

Hudson, T., Detmer, E., \& Brown, J.D. (1995). Developing prototypic measures in cross-cultural pragmatics. (Tech. Rep. No. 7). Honolulu: University of $\mathrm{Ha}$ waii at Manoa, Second language Teaching and Curriculum Center.

Hyland, K. (1998). Hedging in scientific research articles, Amsterdam: John Benjamins.

Johnson, D. (1992). Compliments and politeness in peer-review texts. Applied Linguistics, 13, 51-71.

Kachru, B. (1982). The other tongue: English across cultures. Urbana, IL: The University of Illinois Press.

Kasper, G. (1997). Can pragmatic competence be taught? Available: http://www.lll. hawaii. edu/NFLQC/ Networks/NML.

Kasper, G. \& Dahl, M. (1991). Research methods in interlanguage pragmatics. Studies in Second Language Acquisition, 13, 215-247.

Kasper, G, \& Schmidt, R. (1996). Developmental issues in interlanguage pragmatics. Studies in Second Language Acquisition, 18, 149-169.

Kubota, R. (1995). Japanese culture constructed by discourses: Implications for 
applied linguistics research and ELT. TESOL Quarterly, 33, 9-36.

LoCastro, V. (1987). Yes, I agree with you, but . . . : Agreement and disagreement in Japanese and American English. JACET Annual Bulletin, 18, 71-87. Also ERIC Document ED 654321.

LoCastro, V. (1996). English language education in Japan. In H Coleman (Ed.), Society and the Language Classroom (pp. 40-58). Cambridge: Cambridge University Press.

LoCastro, V. (1998a). Lecture notes. International Christian University, Spring.

LoCastro, V. (1998b, March). Learner subjectivity, motivation, and pragmatic competence development. Paper presented at The 3rd Pacific Second Language Research Forum, Tokyo.

LoCastro, V. (1999, August). Variation in the use of mitigation in opinion-giving academic essays. Paper presented at AlLA (Association de Linguistique Appliquée) 1999, Tokyo.

LoCastro, V., \& Sasaki, M. (1998, March). Mitigation in the English essays of Japanese learners. Paper presented at TESOL'98 Conference, Seattle.

Masumi-So, H. (1998, March). Research into the norms of interaction in NS-NSS contact situation-whose norm is it? Paper presented at The 3rd Pacific Second Language Research Forum, Tokyo.

McNamara, T.F, (1997). 'Interaction' in second language performance assessment: Whose performance? Applied Linguistics, 18, 446-466.

Mey, J.J. (1985). Whose language? A study of linguistic pragmatics. Amsterdam/ Philadelphia: John Benjamins.

Mey, J.J. (1993), Pragmatics: An introduction. Oxford: Blackwell.

Myers, G. (1989). The pragmatics of politeness in scientific articles, Applied Linguistics, 10,1-35.

Nelson, G.L., \& Carson, J.G. (1998). ESL students' perceptions of effectiveness in peer response groups. Journal of Second Language Writing, 7, 113-131.

Netsu, M, \& LoCastro, V. (1997), Point of view and opinion-giving in discussion tasks. Proceedings of the 8 th conference on second language research in Japan (pp. 136-153). Tokyo: International University of Japan.

Nikula, T. (1997). Interlanguage view on hedging. In R. Markkanen \& H. Schroeder (Eds.), Hedging and discourse: Approaches to the analysis of a pragmatic phenomenon in academic texts (pp. 188-207). Berlin: Walter de Gruyter.

Peirce, B.N. (1995). Social identity, investment, and language learning. TESOL Quarterly 29 (1), 9-32.

Pomerantz, A.M. (1984). Agreeing and disagreeing with assessments: some features of preferred and dispreferred turn shapes. In J.M. Atkinson \& J. Heritage (Eds.), Structures in social action; Studies in conversational analysis (pp. 57101). Cambridge: Cambridge University Press.

Sato, H., \& Beecken, M. (1997), An approach to instruction in pragmatic aspects: Implications of pragmatic transfer by American learners of Japanese. Modern Language Journal, 81, 363-377.

Takahashi, T., \& Beebe, L. (1993). Cross-linguistic influence in the speech act of correction. In G. Kasper \& S. Blum-Kulka (Eds.), Interlanguage pragmatics (pp.138-157). Oxford: Oxford University Press. 
Tateyama, Y., Kasper, G., Mui, L.P., Tay, H.M., \& Thananart, O.O. (1997). Explicit and implicit teaching of pragmatic routines. In L. Bouton (Ed.), Pragmatics and Language Learning, 8, 163-177. University of Illinois at UrbanaChampaign.

Urmason, J.O (1952). Parenthetical verbs. Mind, 61, 480-496.

(Received March 18, 2000; revised June 12, 2000)

\section{Appendix}

Peer Review Task

Directions: You have been given the essay draft of another student who also has your essay. I would like you to write a letter to your classmate about his/ her essay. After I look at your letter, your classmate will get the letter to read on Friday. In your letter, please comment on the following areas:

1. Make some positive comments as well as comments about how the writer (your classmate) could improve his or her essay.

2. Give some critical comments about grammar, spelling, word choice, the contents of the essay, the organization (introduction, body, and conclusion), development of the ideas, evidence of critical thinking, reading, and writing.

3. Suggest some corrections.

4. Look for the topic sentences and thesis statements (which should give the main idea of the entire essay). Comment on these.

5. Look for supporting evidence for ideas in the essay. Make suggestions about this important feature of an essay.

6. Finally, give your reaction to the essay. 